\title{
Macro social theory, linguistic ethnography and interpreting research
}

\author{
Moira Inghilleri \\ Goldsmiths College, University of London
}

This article presents an outline of a sociological and linguistic-ethnographic perspective as applied to contexts of community interpreting. It describes a theoretical and methodological approach which, drawing on Toury's descriptivist theory of norms and Bourdieu's social reproduction theory, considers how relevant macro-social features impact on interpreting activity. This approach has as its aim to theorise configurations of the social in local interpreting contexts and to demonstrate how interpreters, as pivotal players in these contexts, are caught up in larger social configurations of power and control, both internal and external to their professional field of practice. It suggests that norms of interpreting activity and training can be linked to the wider social and political contexts of their occurrence. A descriptive language of interpreted events is developed which reflects participants' embeddedness in social and political processes, and how this impacts on both actual and potential discursive moves within interpreted interactions. The sociological and linguistic-ethnographic perspective takes the view that what happens at the surface level of interactions is more often than not a micro drama through which a larger social and political reality is acted out in a refracted form.

\section{Introduction}

This article considers the role that sociological and linguistic-ethnographic perspectives can contribute to theoretical and methodological approaches to community interpreting research. The sociological-linguistic ethnographic perspective outlined below has as its aim to theorise configurations of the social in local interpreting contexts. It also theorises how interpreters, as pivotal players in these contexts, may contribute to the production or reproduction of the existent social order. Rather than taking micro-textual features per se as the primary locus of data, this approach takes the macro-social as its starting point in order to address the fundamental issue of what constraints there are on interpreting more broadly. Its methodological concerns are not with the micro-level features of interpreted exchanges themselves, but with how these exchanges are socially and institutionally framed. The perspective taken is that the ways interpreters work are influenced by the social and political contexts in which both their work and the training that may inform their professional practice occur. It maintains that interpreters - though not unreflexively - are caught up in larger social configurations of power and control both internal and external to their profes- 
sional field of practice. While the primary focus is on the macro-level, the approach is empirical. Data is generated using standard ethnographic methods, including observation of relevant sites, interviewing of key participants and examination of relevant written documentary texts.

The aim of a sociological and linguistic-ethnographic approach to research in community interpreting is to develop a descriptive language of interpreted events which is capable of comprehending participants' embeddedness in social and political processes and capturing the wider implications of particular moves within interpreted interactions. It takes the view that what happens at the surface level of interactions is more often than not a micro drama through which a larger social and political reality is acted out in a refracted form. The use of discourse analytic methods in interpreting research as applied to legal, medical and other community-based contexts has revealed much about the complexity of the interpreter's role in interaction. The various findings of this type of research have challenged the norm of the interpreter's invisibility and demonstrated the potential for interpreters to influence and even dominate, rather than mimic communication between interlocutors. Ultimately, however, micro-level discourse analytical approaches to interpreting research tell us more about the particular realisations of discourse processes within interpreted interactions than about interpreters as active agents in wider social and political processes. Indeed, the conclusion often drawn in such research is that interpreters must be more faithful to language, better mimickers, ascribing to a 'language as client' model. This suggests a view of discourse, including its pragmatic aspects, and of interpreters themselves, as in some way abstractable from the wider social and ideological processes informing professional conduct. But interpreters, as well as the norms generating their communicative practices, do not come from nowhere. They too are socially and politically situated, actively participating in the production and reproduction of macro-discursive practices.

\section{Norms, contingency and the interpreting habitus}

Within interpreting studies research, very little attention has been paid to the development of sociologically informed models of professional activity. This is not true of translation studies, however. The well-established descriptivist tradition, for example, has as its main concern to examine processes and products of translation beyond the translator and the text and within complex configurations of macro-social and historical contexts. The area of descriptivism that has been most pertinent to the approach to interpreting discussed here is Gideon Toury's work on norms (Toury 1995 and see Shlesinger 1989; Harris 1990; Schjoldager 1995/2002 with respect to interpreting contexts). Norms have been described as "internalized behavioural constraints which embody the values shared by a community and govern those decisions in the translation process which are not dictated by the two language systems involved" (Hermans 1999). With respect to trans- 
lational/interpreting activity, norms operate on translators/interpreters' decision-making in a largely unconscious way and are independent of the linguistic environment alone. Important as this work has been for considering the impact of social and cultural processes on translation and interpreting activity, however, it has remained overly descriptive, lacking an adequate conceptualisation of how norms emerge and are sustained simultaneously at the conscious and unconscious level.

Within translation studies there has been a recent shift toward more sociologically and anthropologically informed approaches which have attempted to address some of these limitations (Hermans 1999; Buzelin 2005; Simeoni 2005; Baker 2006). Amongst these, Bourdieu's social theory has been shown to offer a powerful set of concepts for analysing both the social nature of translation and interpreting activity and the role of translators and interpreters as social and cultural agents. Bourdieu's key notions of field, habitus, captial and illusio have been taken up in different ways by numerous scholars (see, for example, Simeoni 1998; Heilbron and Sapiro 2002; Inghilleri 2005b) to demonstrate the relationship between process and product, agency and structure, creativity and constraint in translation and interpreting activity

My own research has in part emerged out of a dialogue within translation studies about whether the field of translation might be said to constitute a field in Bourdieu's sense. Bourdieu defines fields as "historically constituted areas of activity with their specific institutions and own laws of functioning" (Bourdieu 1990: 87). For Bourdieu, fields are relatively autonomous social microcosms that constitute a network of objective relations between objectively defined positions of force within social space. Each field is defined by specific stakes and interests which operate both in relation to other fields and within the same field. It is within the context of particular fields and through the habitus - embodied dispositions acquired through individuals' social and biological trajectories and continually shaped and negotiated vis-à-vis fields - that social agents establish and consolidate their positions in social space. Within translation studies, it has been suggested that, as an outcome of norms of training and practice, translators have come to embody notions of servility and invisibility that define their habitus, at the expense of a more visible and creative sense of themselves and their role. They have become "nearly fully subservient: to the client, to the public, to the author, to the text, to language itself, or even, in certain situations of close contact, to the culture or subculture within which the task is required to make sense" (Simeoni 1998: 12).

In considering these issues with regard to interpreters and the interpreting profession, I have suggested (Inghilleri 2005a) that interpreting be viewed not as a field in Bourdieu's sense but as a "zone of uncertainty", Bourdieu's term for the potentially liberatory spaces within a social structure in which contradictions emerge from a convergence of conflicting world-views that momentarily upset the relevant habitus. Bourdieu suggests that zones of uncertainty are located in the gaps or spaces between fields hence their lack of clear social definition. However, this conceptualisation 
leaves open the question of how particularly ill-defined professions like community interpreting are actually socially constituted and why this constitution leaves them socially vulnerable. In order to address this question, a further description is needed for: how the convergence of conflicting worldviews that structures the interpreted event comes about; why interpreters are more vulnerable than others in this social/interactional space; and by what means the liberatory potential of the discordancy evident in zones of uncertainty can be realised.

The notion of a zone of uncertainty permits us to view interpreting as an instantiation of a convergence of fields, i.e., social/institutional/discursive practices that through a combination of specialised knowledge and networks of power have become established and taken for granted within specific social and historical contexts. Importantly, however, in interpreted events, these practices are brought into a new relationship - the relationship between the various practices is recontextualised - they come together as new forms of knowledge or sets of understandings. Understood in this way, interpreting activity is neither a field or a mere lacuna in social space but is a concrete site for the convergence - through a process of recontextualisation - of inter-locking fields and their accompanying habitus.

This conceptualisation of interpreting activity clarifies the means by which zones of uncertainty, although they represent relatively weak social positions, are nevertheless endowed with the potential to create new forms of legitimate social practice. The possibility and ultimate strength of any new form of legitimacy, however, lies in the dynamic between the hierarchical field relations, their accompanying habitus and those of the social agents involved in the reconstitution of the social order. These agents, who in community interpreting contexts might include, for example, judges, solicitors, doctors, service providers or teachers, will possess culturally significant forms of capital linked to their respective fields that confer prestige, status and authority upon them. These fields are part of the larger universe of symbolic institutions that reproduce existing power relations through the production and distribution of a dominant culture that tacitly confirms what counts as legitimate linguistic and cultural knowledge in the institutional context. Interpreting activity and the specific realisation of the interpreters' role thus remain contingent upon the conditions of their recontextualisation in relation to other fields and their social agents.

While the norms of both interpreter training institutions and professional practice tend toward subservience of the kind described above, I would suggest that the question of subservience to others be viewed not as a given, but as a potential realisation of the interpreter role. In a given interpreting context, distinctive, contradictory or conflicting habitus operating amongst the relevant participants, including interpreters, suggests the likelihood of some degree of negotiation over the social/interactional space (Inghilleri 2003). As noted above, micro-interactional analysis of interpreted events has provided ample evidence of such negotiation, conscious or otherwise, over participatory roles across a range of community interpreting contexts (Wadensjö 1998; Mason 1999; Hale 2004; Bot 2005). Un- 
fortunately, however, there is much inconsistency in this research with regard to the various implications of its findings - it is not always clear whether interpreters are being blamed by researchers for too little or too much subservience. This inconsistency may in part reflect the uncertainty in interpreting training, practice and research regarding what actually constitutes a community interpreting context.

In my research on interpreting in the political asylum system, different sets of expectations and practices regarding the interpreter's role were evident across the range of contexts comprising the application process. The presence of a solicitor, moreover, was not always a guarantee of effective advocacy. Under such circumstances, interpreters in a more formal legal setting might be called upon or feel compelled to intervene in ways that, according to norms of training, should be restricted to a more communitybased interpreting context.

Ultimately, norms of community-interpreting training and practice are realised within interpreted events which are, as suggested above, complex and ill-defined social/interactional spaces in which linguistic and cultured meanings are rarely static and under frequent negotiation.

I have previously referred to this reconfigured space as the site for the emergence of a distinctive 'interpreting habitus' (Inghilleri 2005a), a term I use to describe the convergence within interpreted events of different world-views/meanings/utterances struggling toward consensus and/or jostling over control of what counts as legitimate linguistic and cultural knowledge. This struggle can take many forms: role confusions that are invoked by the situation; the ambiguities present in certain contexts; the expectations placed on interpreters from others; and the convergence of the institutional, biographical and social features within the interpreting process, all of which may provoke the kind of discordancy from which, as Bourdieu suggests, different forms of legitimate social practice may emerge.

Crucially, however, it is highly likely that in any given interpreted event, the participants positioned within well-established fields and their accompanying habitus will re-produce with a greater degree of certainty than interpreters what they feel to be the 'objective' structures of their respective fields. Moreover, they will possess socially and culturally significant forms of capital which guarantee them greater prestige and authority in the social/interactional space. Interpreters are less socially and cognitively anchored within this space due to the contingent nature of their role. Consequently, they may have a less embodied 'feel for the game', less tacit knowledge and control of this space. Bourdieu's concept of illusio (from ludos, game) refers to this tacit knowledge which allows social agents, relatively unquestioningly, to make sense of what is happening around them and to make decisions as to which "practices, discourses, moves or forms of capital are appropriate to the moment" (Schirato and Webb 2002: 256). But while the contingent nature of their role may render interpreters less socially and interactively certain, it may paradoxically contribute to the disruption of dominant discursive practices. Disruptions, for example, that take the form of a metadiscourse on discourses themselves, may result in greater 
reflection upon the limitations of the habitus, providing participants with greater distance from the process of being produced and spoken by their respective fields $(i b i d)$, leading to breaks or fissures within the social/interactional order.

\section{Discursive gaps, communication rights and meaning in the interpreting context}

Thus far, the perspective discussed above has attempted to theorise the social position and positioning of interpreters within interpreted interactions. Toury's concept of norms and Bourdieu's concepts of habitus, field, capital and illusio have contributed to the development of a language of description which conceives of interpreted events as embedded in wider social, cultural and ideological processes. In addition to these concepts, the notion of recontextualisation has been incorporated into the language of description to underscore both the contingent nature of the interpreter role and the possibility of discordance, disruption and negotiation over the social/interactional ordering of interpreted events. The role of micro-level instantiations of social/institutional/discursive practices has been referred to only in order to highlight differences between the perspective taken here and discourse analytical approaches to interpreting research. While the latter takes actual discourse as its starting point, the concern here is to theorise the social/interactional conditions under which interpreters may claim communication rights as well as the extent and type of rights they may claim. It is under these conditions that actual discourse and potential discourse meet.

As suggested above, the convergence of distinctive fields and habitus within interpreted interactions and the contingent nature of the interpreter's role within these, may create significant discordancy within the social/interactional space which may trigger discursive gaps between local, interactional practices and the socially constituted norms that function to suppress contradictions and struggles over legitimate forms of communication. It is at these points - where the internal logic of official fields and discursive practices become more transparent - that the possibility for change or challenge to existing social relations and communicative practices can occur.

These discursive gaps, as I have suggested elsewhere (Inghilleri 2003), are similar to the 'phronetic gap' between a rule and its enactment identified by Charles Taylor (Taylor 1993: 57) or what Hermans has described in relation to translational activity as "the gap between the concrete enactment of a disposition and a norm or rule and its formulation and representation"(Hermans 1999: 135). Basil Bernstein has referred to such gaps as "the meeting point of order and disorder, of coherence and incoherence" (Bernstein 1990: 182). In my own research (Inghilleri forthcoming) I have found evidence for this type of discursive gap emerging from the tension between interpreted interactions that are oriented toward genuine mutual understanding or democratic iterations (Benhabib 2004; and see Derrida 1988; Butler 
1997) and those oriented toward authorised discourses (Bourdieu 1991) in which pre-established power relations are maintained.

The notion of a democratic iteration suggests the possibility of meaning - and thus social or cultural knowledge - that is not weighed down or over-determined by prior contexts or position holders. It suggests, for example, that references to diverse linguistic, cultural or religious beliefs or practices that feature frequently in contexts of community interpreting can be taken up constructively in a context of dialogue that does not require shared meaning or understanding as a precondition. It suggests that the capacity of the force of an utterance to assume new contexts - which Derrida suggests emanates in language itself - can create the necessary conditions for the emancipatory potential of partners in cross-cultural contexts of communication to create new meanings which themselves remain unfixed to any one context.

Authorised discourse, on the other hand, reflects Bourdieu's view that the efficacy of speech derives not from language but from the institutional conditions of its production and reception. For Bourdieu, language cannot perform a break with context - the power of language cannot be invoked linguistically, authority comes to language from the outside, hence the impossibility that iterations and the discursive gaps which they create, might become the source of challenges to socially pre-established grounds of legitimate meanings. This is so in large part because social agents are generally oriented toward correction or adaptation - as restoring order of a kind - making it unlikely that such gaps will be transformed into overt or covert strategies of resistance to the social order. For Bourdieu, the contributory role of rational, speaking subjects - constituted in and by networks of practice - cannot be viewed as a potential activator of the transformative capacity of the habitus.

I would argue, however, that interpreters are key activators of such transformations, consciously or not, as active participants in the interplay between the force of democratic iteration and that of authorised language. As suggested above, the interpreting habitus is a collective embodiment of the convergence of world views/meanings/utterances within the interpreted event. Although participants' responses to this convergence may differ depending on the context, all are socially and interactionally challenged in their conscious or unconscious struggles for social/interactional control or consensus over communication rights and ultimately, meaning.

\section{The paradoxes and potentials of the interpreting habitus}

The following extracts, taken from interviews collected in my research on the interpreter's role in the political asylum system in the UK, illustrate some of the divergent understandings and realisations of the interpreter role evident in participants' accounts of actual interpreted events and of their pre-established expectations of these events. I will offer a brief commentary 
here on these examples which I believe give expression to the interplay between democratic iteration and authorised discourse discussed above.

In the first two examples, both speakers are experienced members of the legal field who work with interpreters on a regular basis and are highly committed to the achievement of just outcomes for their clients in the political asylum system. The speaker in Example 1, however, expresses a view and her right to exercise this view in the interpreted event - which denies the legitimacy of an interpreter's cultural or linguistic knowledge in the context of the client interview. In Example 2, in contrast, an interpreter's cultural or linguistic knowledge is viewed as having the potential to inform and interfere with the client interview.

\section{Example 1}

Well an interpreter is effectively, in my view, the mouthpiece of the client, nothing more, nothing less. They're not supposed to impose their views on, on what they think you should be asking the client, or attempt to influence the interview in any way. We've all come across instances where a client gives a particular answer and you ask another question, a supplementary question, and the interpreter sort of interferes and says, "Well that is what happens in my country" and that's nothing at all to do with them. (Solicitor)

\section{Example 2}

...a very good interpreter can provide you with assistance with a lot of background information because when we grow up with something, we grow up with a set of experiences, we assume that everybody else has exactly the same understanding of the circumstances we do ... And because clients, and people generally will normally assume you have a much greater understanding of a situation, or will assume that the Home Office either have a care or an understanding of the background of the cases, that they will often leave a great deal unsaid because they just assume that you know it. And a good interpreter will sort of, may nudge you in the right direction, see what he's talking about, because he's not bringing it out properly, 'what I think he's talking about is this', to give you the opportunity to ask further questions . (Solicitor)

In their comments, each speaker expresses a distinctive understanding of their social/interactional position and that of interpreters within interpreted events. The first example suggests the privileging of authorised discourse, and the second, of democratic iteration. What is of interest in these examples is not which of these views may be right or wrong, which more appropriately follows established interpreting norms, or indeed, which legal rep- 
resentative is more likely to effectively represent their client. What the speakers demonstrate is the contingency of the interpreter's role discussed above, and of their linguistic and cultural knowledge, which, paradoxically, is the most valuable form of capital they bring to the interpreted event, i.e., it is the minimal requirement needed to train and work as an interpreter.

In Example 3, an experienced interpreter describes a conflicting convergence of world-views between interpreters and clinicians regarding clients' needs within interpreted events in a mental health setting. In the particular convergence described here, the prestige and authority guaranteed to the clinician based on her membership in the medical field are treated as secondary to her inexperience in working with interpreters in a clinical setting. The resulting process of negotiation over social/interactional rights described by the speaker, e.g., who sits where, who looks at whom, the extent of the interpreter's right to be present and, ultimately, whose experience counts as legitimate, is an interesting illustration of the interplay between democratic iteration and authorised language. The divergent views here are not found between two members of the same field, as in the examples above, but between interpreters and other more 'socially-certain' professionals within the interpreted event.

\section{Example 3}

We sometimes sense, even if they don't say directly, we feel it sometimes, we are told there are clinicians who may be I would say inexperienced, inexperienced in working with interpreters I mean. They will say, "Look. you are my mouth and my ears", and "Oh will you just sit down behind me so I would have eye contact with the client". And things like that do happen, but eventually I think we come to conclusion that it doesn't work because the client has to be very comfortable in a session, first to be able to get off whatever on his chest. And secondly the client naturally will look at the person who speaks his language. So I wouldn't take that as a threat or being unprofessional from interpreters. But if you speak my language I will turn to look at you, unless I am told, forced to look at [ ] as I said, the whole goal is to help the client, and the client, if he manages to give everything he wants and we manage to give him something that he wants, fine, so... (Interpreter)

The final example is an excerpt of an interview conducted between myself (M) and an asylum adjudicator (A). The adjudicator is discussing the dilemma she faces when she senses or sees what she takes to be a sign of a conflicting world-view between interpreters and appellants, in this case, Eastern European interpreters and Roma Gypsies. In her comments, the adjudi- 
cator likens the embodied ("sitting three feet away") social/interactional position of the interpreter with respect to the appellant to that of a predator - a predator who is also socially and interactionally present in her courtroom as an interpreter:

A: Well, there have been instances in the past where I have had Eastern European interpreters, with perhaps a Roma gypsy, and I can immediately see that the predator that they [the Roma] face in their own country is sitting right next to them, because they [the Interpreters] are sitting three feet away, whereas normally you would expect the distance to be a normal sort of chair, perhaps eighteen inches, that sort of thing

M: Yes, and does that, I mean apart from the kind of unpleasantness of that in the space that they're occupying, does that concern you that then it would be affecting the interpreter's ability or willingness or in some ways distort the interpreter's role?

A: Yes, well, I'm conscious of that, and I think in those circumstances it's important to keep the questions straightforward and simple, but it's very easy when you're speaking English to, or any language I guess, to make a very convoluted question. And if you've got to the point where I felt that it was affecting, although your question is how would I know it was affecting, then I would just stop and adjourn and give them another interpreter. But I have, in the appeals system we have written statements, we have what they've said in the past, so provided nothing, if something totally different came out, and I thought the interpreter was misinterpreting, I would stop immediately.

The adjudicator describes a moment of conscious awareness of interpreters as social agents who, under specific circumstances, may themselves operate through an authorised discourse. In this case, the potential for interpreters to control the social/interactional space is derived from the social world beyond the courtroom, but also from their control over language itself within the interpreted event. In an attempt to counter or resist this control, the adjudicator claims to consciously adjust her language, to keep her questions more unambiguous and, if necessary, to rely on previous written statements (which would, of course, also have been produced with the services of an interpreter or translator) or, if all else appears to fail, to cease communicating with the interpreter altogether.

Each of these examples, in different ways, highlights the inherently social nature of interpreted interactions and the various ways that all who participate are situated within the wider social, institutional and discursive frameworks of the interpreting activity. While the interpreter's position may 
be ultimately contingent on more powerful players within the interpreted event, i.e., the solicitors may be the ones who determine the interpreter's role and only the adjudicator can adjourn the hearing, ultimately all participants enter a zone of uncertainty in the social/interactional space of the interpreted event, where discursive gaps may at any point appear. Acts of interpreting are, like all acts of communication, by their very nature, meeting points of social and linguistic order and disorder. The language of description developed here is intended to bring some theoretical and methodological order to the complex and paradoxical social, cultural and linguistic realities of interpreted events.

\section{Bibliography}

Baker, Mona (2006). Translation and Conflict. London: Routledge.

Benhabib, Seyla (2004). The Rights of Others: Aliens, Residents and Citizens. Cambridge: Cambridge University Press.

Bernstein, Basil (1990). The Structuring of Pedagogic Discourse: Class, Codes and Control, vol. $I V$. London: Routledge.

Bourdieu, Pierre (1990). In Other Words: Essays toward a Reflexive Sociology. Stanford: Stanford University Press.

Bourdieu, Pierre (1991). Language and Symbolic Power. Cambridge: Polity Press.

Bot, Hanneke (2005). Dialogue Interpreting in Mental Health. Amsterdam/New York: Rodopi.

Butler, Judith (1997). Excitable Speech. London: Routledge.

Buzelin, Hélène (2005). "Translation Studies, Ethnography and the Production of Knowledge." Paul St-Pierre \& Prufella C. Kar (eds). In Translation: Reflections, Refractions, Transformations. New Delhi: Pencraft International, 25-41.

Derrida, Jacques (1988). "Signature, Event and Context". Gerald Graff (ed.). Limited Inc. Evanston: Northwest University Press, 1-23.

Hale, Sandra Beatriz (2004). The Discourse of Court Interpreting. Amsterdam/Philadelphia: John Benjamins.

Harris, Brian (1990). "Norms in Interpretation.” Target 2(1), 115-119.

Heilbron, Johan \& Sapiro Gisèle (eds) (1999). "Traduction: Les éschanges littéraires internationaux". Special issue of Actes de recherche en sciences sociales. Paris: Éditions du Seuil.

Hermans, Theo (1999). Translation in Systems: Descriptive and System-oriented approaches explained. Manchester: St. Jerome Publishing.

Inghilleri, Moira (2003). "Habitus, field and discourse: Interpreting as a socially-situated activity". Target 15(2), 243-268.

Inghilleri, Moira (2005a). "Mediating Zones of Uncertainty: interpreter agency, the interpreting habitus and political asylum adjudication". The Translator 11(1), 69-85.

Inghilleri, Moira (2005b). "The sociology of Bourdieu and the construction of the 'object' in translation and interpreting studies". The Translator 11(2), 125-145.

Inghilleri, Moira (forthcoming) "National sovereignty vs. universal rights: interpreting justice in a global context", Myriam Salama-Carr (ed.). Translation and Conflict, Special Issue of Social Semiotics 17.

Mason, Ian (ed.). (1999). "Dialogue Interpreting". Special issue of The Translator 5(2).

Schirato, Tony \& Jen Webb (2002). "Bourdieu's Notion of Reflexive Knowledge". Social Semiotics $12(3), 255-268$.

Schjoldager, Anne (1995/2002). "An Exploratory Study of Translational Norms in Simultaneous Interpreting: Methodological Reflections.” Franz Pöchhacker \& Miriam Shlesinger (eds). The Interpreting Studies Reader. London: Routledge, 301-311.

Shlesinger, Miriam (1989). "Extending the theory of translation to interpretation: Norms as a case in point". Target $1(1), 111-115$.

Simeoni, Daniel (1998). "The pivotal status of the translator's habitus". Target 10(1), 1-39.

Simeoni, Daniel (2005) "Translation and Society: The Emergence of a Conceptual Relationship." Paul St-Pierre \& Prufella C. Kar (eds). In Translation; Reflections, Refractions, Transformations. New Delhi: Pencraft International, 3-14. 
Taylor, Charles (1993). "To Follow a Rule..." Craig Calhoun, Edward Li Puma \& Moishe Postore (eds). Bourdieu: Critical Perspectives. Cambridge: Polity Press, 45-60.

Toury, Gideon (1995). Descriptive Translation Studies and Beyond. Amsterdam/Philadephia: John Benjamins.

Wadensjö, Cecilia (1998). Interpreting as Interaction. London: Longman. 